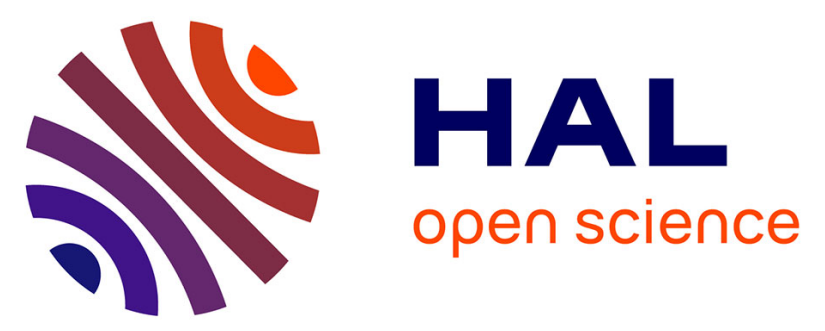

\title{
Correlation between the proton conductivity and diffusion coefficient of sulfonic acid functionalized chitosan and Nafion composites via impedance spectroscopy measurements
}

Ibtissam Ressam, M. Lahcini, A. Belen Jorge, Hubert Perrot, Ozlem Sel

\section{To cite this version:}

Ibtissam Ressam, M. Lahcini, A. Belen Jorge, Hubert Perrot, Ozlem Sel. Correlation between the proton conductivity and diffusion coefficient of sulfonic acid functionalized chitosan and Nafion composites via impedance spectroscopy measurements. Ionics, 2017, 23 (8), pp.2221-2227. 10.1007/s11581-0172151-5. hal-01609912

\section{HAL Id: hal-01609912 \\ https://hal.sorbonne-universite.fr/hal-01609912}

Submitted on 12 Oct 2017

HAL is a multi-disciplinary open access archive for the deposit and dissemination of scientific research documents, whether they are published or not. The documents may come from teaching and research institutions in France or abroad, or from public or private research centers.
L'archive ouverte pluridisciplinaire HAL, est destinée au dépôt et à la diffusion de documents scientifiques de niveau recherche, publiés ou non, émanant des établissements d'enseignement et de recherche français ou étrangers, des laboratoires publics ou privés. 


\title{
Correlation between the Proton Conductivity and Diffusion Coefficient of Sulfonic Acid Functionalized Chitosan and Nafion Composites via Impedance Spectroscopy Measurements

\author{
I. Ressam, ${ }^{[\mathrm{a}, \mathrm{b}]}$ M. Lahcini, ${ }^{[\mathrm{b}]}$ A. Belen Jorge, ${ }^{[\mathrm{c}]}$ H. Perrot, ${ }^{*[\mathrm{a}]}$ O. Sel ${ }^{*[\mathrm{a}]}$
}

[a] Sorbonne Universités, UPMC Univ. Paris 06, CNRS, Laboratoire Interfaces et Systèmes Électrochimiques, 4 place Jussieu, F-75005, Paris, France.

[b] Cadi Ayyad Université, Faculté des Sciences et Techniques, Laboratoire Chimie Organométallique et Macromoléculaire -Matériaux Composites - Marrakech, Maroc.

[c] Materials Research Institute, School of Engineering and Materials Science, Queen Mary University of London, Mile End Rd, E1 4NS, UK.

Corresponding authors: ozlem.sel@upmc.fr (+33 01442796 15) hubert.perrot@upmc.fr (+33 0144 $277216)$

\begin{abstract}
:
Electrochemical Impedance Spectroscopy (EIS) was employed to estimate the global transverse proton diffusion coefficient, $\mathrm{D}_{H}{ }^{+}$, in sulfonic acid functionalized sustainable chitosan $(\mathrm{CS}-\mathrm{SO} 3 \mathrm{H}) / \mathrm{Nafion}$ composite films. In contrast to conventional conductivity measurements, EIS measurements were performed at room temperature with a film/liquid interface. In this configuration, the measure of the bulk proton transport is correlated to the ${D_{H}}^{+}$of the membranes which is close to $1.1 \times 10^{-6} \mathrm{~cm}^{2} \mathrm{~s}^{-1}$ and 0.33 x $10^{-6} \mathrm{~cm}^{2} \mathrm{~s}^{-1}$ with and without $\mathrm{CS}-\mathrm{SO}_{3} \mathrm{H}$, respectively. These $D_{H}{ }^{+}$values permitted the proton conductivity $\left(\sigma_{\mathrm{H}}{ }^{+}\right)$ratio $(\sim 3.9)$ between the Nafion/CS-SO $3 \mathrm{H}$ composite and pristine Nafion films to be estimated by using the Nernst-Einstein relationship. This ratio presents a good agreement with that obtained for the $\sigma_{\mathrm{H}}{ }^{+}$of bulk membranes $(\sim 3.2)$ measured at $30{ }^{\circ} \mathrm{C}$ and $90 \% \mathrm{RH}$. The agreement between the $\sigma_{\mathrm{H}}{ }^{+}$ratios validates our methodology for $D_{H}{ }^{+}$estimation by EIS and suggests that the more than 3 times enhanced $\sigma_{\mathrm{H}}{ }^{+}$is governed by the $\sim 3$ times higher $D_{H}{ }^{+}$in the presence of CS-SO $3 \mathrm{H}$.
\end{abstract}




\section{Keywords:}

Diffusion coefficient $\bullet$ proton conductivity $\bullet$ impedance spectroscopy $\bullet$ sulfonic acid functionalized chitosan $\bullet$ Nafion composites.

\section{Introduction}

Research in energy generation, conversion and storage have drastically increased due to the need for a sustainable energy infrastructure [1a-c]. The electrochemical devices such as fuel cells, redox flow batteries and solar-fuel generators are made of several functional layers and a combination of materials with various physical processes and chemical reactions. These processes include ionic conduction and generally require the charged intermediates (e.g. protons, hydroxide ions) to be transported through a solid-state ion conducting polymer membrane and be transferred at an interface where the redox reactions occur [2a-c]. Therefore, perfluorinated sulfonated acid (PFSA) ionomer membranes such as Nafion plays a central role as separators in fuel cells and regaining interest in aqueous rechargeable or redox-flow batteries [3a-e].

Specifically, proton diffusion studies in Nafion membranes have been conducted to understand its mechanism and eventually to help in designing alternative polymer electrolyte membranes (PEMs) with improved properties. Among the methods employed for this purpose, pulsed field gradient (PFG) NMR [4a-c] and quasielastic neutron scattering (QENS) [5a,b] studies can be emphasized. Besides experimental methods, classical molecular dynamic simulations have been used to study $\mathrm{H}^{+}$dynamics [6], and recent progress in modelling and simulation studies provided theoretical methods to account for structural diffusion which are capable of describing changes in bonding topology between water and mobile protons $[7 \mathrm{a}-\mathrm{d}]$.

In spite of a relatively large number of experimental methods available to study the diffusion coefficient of $\mathrm{H}^{+}$in bulk materials, direct measurements giving access to proton diffusion in proton conducting films are scarce. The increasing demand for proton conductors with improved properties requires appropriate characterization tools to assess key parameters of newly developed solid electrolytes. 
Here, a method based on the electrochemical impedance spectroscopy (EIS) is reported to estimate the diffusion coefficients in PFSA ionomer films [8a-d]. It constitutes one of the very few methods allowing the diffusion coefficient estimation even for micrometer thick films.

Nafion's chemical structure is composed of a perfluorinated backbone that provides both chemical and mechanical stability, and randomly placed tethered perfluoroether side chains terminated by sulfonic acid groups, which impart its remarkable proton-conduction capabilities [2c, 3b]. Similarly, in this study, a sustainable chitosan polymer [9a-d] was modified in the presence of sulfosuccinic acid (SSA) $\left(\mathrm{CS}-\mathrm{SO}_{3} \mathrm{H}\right)$ to create $-\mathrm{SO}_{3} \mathrm{H}$ groups. Then, modified chitosan was used as a sustainable additive to Nafion 117 . Structural and morphological characterization to evaluate the effect of the additives on proton conduction indicates an alteration of the nanostructure of the hydrophilic/hydrophobic interfaces in protonic membranes [8d]. These nanostructural changes must have an impact on the proton transport properties. Therefore, EIS was used non-conventionally to evaluate the impact of modified chitosan additives on the diffusion coefficient of Nafion 117.

\section{Experimental and Theoretical Section}

Materials: Silicomolybdic acid solution $\left(\mathrm{H}_{4} \mathrm{SiMo}_{12} \mathrm{O}_{40}\right)$, pyrrole monomer, chitosan of medium molecular weight (viscosity: 200 - $800 \mathrm{cps}$ and a deacetylation degree of $\sim 80 \%$ ), $70 \mathrm{wt} \%$ sulfosuccinic acid (SSA) in water, Nafion 117 solution (5 wt. \% in lower aliphatic alcohols and water), glacial acetic acid and nitric acid (68\%) were purchased from Sigma-Aldrich.

Sulfonic acid functionalization of chitosan: $0.1 \mathrm{~g}$ of chitosan was dissolved in $25 \mathrm{ml} 2 \mathrm{wt}$ \% acetic acid solution with constant stirring for approximately $3 \mathrm{~h}$ at room temperature (RT). The equivalent molar of sulfosuccinic acid solution $\left(70\right.$ wt. $\%$ in $\left.\mathrm{H}_{2} \mathrm{O}\right)(0.58 \mathrm{mmol})$ - with respect to $-\mathrm{NH}_{2}$ groups - was added to the chitosan solution and vigorously stirred at RT for $24 \mathrm{~h}$. The resulting solution was poured into a Teflon mould and kept at $60^{\circ} \mathrm{C}$ for $8 \mathrm{~h}$. Modified chitosan powder $\left(\mathrm{CS}-\mathrm{SO}_{3} \mathrm{H}\right)$ was dried at $100^{\circ} \mathrm{C}$ in a vacuum oven for $2 \mathrm{~h}$. 
Composite Membrane Preparation: $4.8 \mathrm{mg}$ of $\mathrm{CS}-\mathrm{SO}_{3} \mathrm{H}$ was added into $2 \mathrm{ml}$ of Nafion117 solution (corresponding to $5 \mathrm{wt} \% \mathrm{CS}_{-} \mathrm{SO}_{3} \mathrm{H}$ in the final membrane). This dispersion was sonicated in an ultrasonic bath at RT for $6 \mathrm{~h}$ followed by stirring at $90^{\circ} \mathrm{C}$ for $4 \mathrm{~h}$ to reach a good dispersion and homogeneity. Finally, the dispersion was cast into Teflon moulds and dried in a furnace for $5 \mathrm{~h}$. The Nafion composite membranes were heat-treated and immersed in $1 \mathrm{M} \mathrm{HNO}_{3}$ for 4 hours for activation which was followed by a washing step with distilled water until neutral $\mathrm{pH}$ (to remove the remaining $\mathrm{HNO}_{3}$ ).

Ppy-HPA/Nafion and Ppy-HPA/Nafion-CS-SO 3 H Bilayers: Heteropolyanion doped pyrrole (PpyHPA) mediator films were electrodeposited on gold substrates which is described elsewhere [8a-d]. An equivalent film thickness of $150 \mathrm{~nm}$ is estimated by FEG-SEM (not shown). Prior to Nafion and Nafion$\mathrm{CS}-\mathrm{SO}_{3} \mathrm{H}$ deposition, the mediator film was equilibrated by cyclic voltammetry (CV), between 0.05 and $0.4 \mathrm{~V}$ vs saturated calomel electrode $(\mathrm{SCE})$ in $\mathrm{HClO}_{4}(0.5 \mathrm{M})$ at $20 \mathrm{mV} . \mathrm{s}^{-1}$.

Ppy-HPA/Nafion and Ppy-HPA/Nafion-CS-SO ${ }_{3} \mathrm{H}$ bilayers were prepared as follows: $4.8 \mathrm{mg}$ of $\mathrm{CS}_{-} \mathrm{SO}_{3} \mathrm{H}$ was dispersed in $2 \mathrm{ml}$ of Nafion 117 solution, $6 \mu \mathrm{L}$ of this solution was deposited on the Ppy-HPA covered gold substrates of $0.2 \mathrm{~cm}^{2}$ (geometric surface area of the electrode). Ppy-HPA/Nafion bilayers were prepared for comparison purposes following the same procedure without the $\mathrm{CS}_{-} \mathrm{SO}_{3} \mathrm{H}$. FEG-SEM images in Fig.1a and b present Ppy-HPA/Nafion and Ppy-HPA/Nafion-CS-SO 3 H bilayers, respectively.

Proton conductivity measurements: A lab-made conductivity cell (with an opening of $0.4 \mathrm{~cm}$ x $2.5 \mathrm{~cm}$ ) is placed in a climatic cabinet (CLIMACELL, Fisher Bioblock Scientific) where it is connected through a BNC connector to the measuring probe of the network analyzer (Agilent 4294A). The frequency is scanned between $40 \mathrm{~Hz}$ and $100 \mathrm{MHz}$ with a $30 \mathrm{mV}$ rms sinusoidal perturbation amplitude of the signal. The resistance of the membranes was determined from the electrical impedance diagrams in the Nyquist representation. The proton conductivity $\left(\mathrm{S} \mathrm{cm}^{-1}\right)$ was calculated using $\sigma=\frac{d}{R \times e \times L}$; where $e$ is the dry membrane thickness $(\mathrm{cm})$ (measured with Mitutoyo dial thickness gauge), $d$ is the opening between the two gold electrodes (and it is considered as the active portion of the membrane $(\mathrm{cm})$ ), $L$ is the width of the membrane $(\mathrm{cm})$ and $R$ is the resistance of the membrane estimated from the electrical impedance 
measurements $(\Omega)$. The method has the sensitivity to measure the values between $0.1 \mathrm{mS} \mathrm{cm}^{-1}$ and at least up to $200 \mathrm{mS} \mathrm{cm}^{-1}$ which is a fairly sufficient range to characterize proton conducting membranes. Typical film thicknesses measured range from a few micrometers to a few tenths of micrometers. Measurements were performed at $30{ }^{\circ} \mathrm{C}$ and at $30-90 \% \mathrm{RH}$ levels.

Electrochemical Impedance Spectroscopy: The electrochemical experiments were carried out in a classical three-electrode cell in $0.5 \mathrm{M} \mathrm{HClO}_{4}$ as electrolyte. The reference electrode was a SCE, the counter electrode was a platinum grid. The modified working electrodes (with a geometrical surface area of $0.2 \mathrm{~cm}^{2}$ ) were polarized at a selected potential, and a sinusoidal small amplitude potential perturbation (30 mV rms) was superimposed between $65 \mathrm{kHz}$ and $0.01 \mathrm{~Hz}$. The resulting signals were sent to the four-channel FRA, which allowed the electrochemical impedance, $\frac{\Delta E}{\Delta I}(\omega)$ to be obtained.

Theoretical Background: Electronic transfer occurs at the gold electrode/mediator film interface (Fig.1 $\mathrm{c}$ and d). For a cathodic potential increase, the protons enter the proton conducting film (PCF) from the solution which constitutes the PCF/solution interface and subsequently diffuse in the PCF up to the PpyHPA/PCF interface, where they are inserted. The derivation of the final transfer function, $\frac{\Delta E}{\Delta I}(\omega)$ for the model taking into account the transport phenomenon is detailed in Ref. [8a-d]. For a small potential perturbation, $\Delta E$, the change of the proton flux, $\Delta J_{H}^{+}$, at $\mathrm{x}=\mathrm{d}$, is equal to:

${ }^{\Delta} J_{H^{+}}(d)=G_{H^{+}}^{H P A / P C F} \Delta E+K_{H^{+}}^{H P A / P C F} \Delta c_{H^{+}}^{H P A}+M_{H^{+}}^{H P A / P C F} \Delta c_{H^{+}}^{P C F}(d)$

where $\Delta c_{H^{+}}^{H P A}$ is the proton concentration in the Ppy-HPA film, $\Delta c_{H^{+}}^{P C F}$ is the concentration of the protons in the PCF, close to the Ppy-HPA/PCF interface $(\mathrm{x}=\mathrm{d}), c_{\max }^{H P A}$ and $c_{\min }^{H P A}$ are the maximum and minimum concentrations of the protons in the Ppy-HPA film, and $k_{i}=k_{i}^{0} \exp \left(b_{i} E\right)$ are the classical Tafel kinetic rate constants. 
$K_{H^{+}}^{H P A / P C F}=k_{1}+k_{2} c_{H^{+}}^{P C F}(d), G_{H^{+}}^{H P A / P C F}=b_{2} k_{2}\left(c_{\max }^{H P A}-c_{H^{+}}^{H P A}\right) c_{H^{+}}^{P C F}(d)-b_{1} k_{1}\left(c_{H^{+}}^{H P A}-c_{\min }^{H P A}\right)$

and

$M_{H^{+}}^{H P A / P C F}=k_{2}\left(c_{\max }^{H P A}-c_{H^{+}}^{H P A}\right)$ are the constants related to the transfer at the Ppy-HPA/PCF interface.

The equation describing the faradic electrochemical impedance, $\frac{\Delta E}{\Delta I}(\omega)$ which takes into account the diffusion phenomenon $\left(\mathrm{j} \omega \Delta C^{H P A / P C F}=D \frac{\partial^{2} \Delta C^{H P A / P C F}}{\partial x^{2}}\right)$ was given in Ref. [8a-d] and is equal to:

$$
\frac{\Delta E}{\Delta I}(\omega)=\frac{1}{F G_{H^{+}}^{H P A / P C F}}\left(1-M_{H^{+}}^{H P A / P C F} \frac{\tanh \left(-L \sqrt{\frac{\mathrm{j} \omega}{D_{H^{+}}^{P C F}}}\right)}{\sqrt{\mathrm{j} \omega D_{H^{+}}^{P C F}}}\right)-\frac{K_{H^{+}}^{H P A / P C F}}{\mathrm{j} \omega d F G_{H^{+}}^{H P A P C F}}
$$

where $L$ is the proton conducting film thickness and $D_{H^{+}}^{P C F}$ is the diffusion coefficient of the protons. The equation 1 was used to fit of the experimental $\frac{\Delta E}{\Delta I}(\omega)$. In our basic approach, to simplify the analytical model, only diffusion is taken into account, the migration effect being considered as a minor contribution. This can be justified by the fact that without a mediator film, which acts as a "proton pump", the electrochemical response is drastically different under the same experimental conditions. This indicates that the main driving force for proton transport is the concentration gradient inside the proton conducting film.

Then, when the proton diffusion coefficient $\left(\mathrm{D}_{H}{ }^{+}\right)$is estimated through a fitting procedure, the proton conductivity can be calculated using the Nernst-Einstein equation [10]:

$$
\sigma_{H}{ }^{+}=\mathrm{F}^{2} \times \frac{D_{H}{ }^{+} \times C_{H}{ }^{+}}{R \times T}
$$

where $\mathrm{F}$ is the Faraday number and $C_{H}{ }^{+}$is the proton concentration in the proton conducting film (estimated from the ion-exchange capacity and the geometric dimensions of the film). 


\section{Results and Discussion}

For EIS measurements, as PFSA ionomers are only ionic conductors, a mediator film, (polypyrrole doped with heteropolyanions, $\mathrm{SiMo}_{12} \mathrm{O}_{40}{ }^{4-}$ (Ppy-HPA) [8a-d, 11]) was introduced between the gold electrode and PFSA ionomer resulting in Ppy-HPA/Nafion and Ppy-HPA/Nafion-CS-SO 3 H bilayers. This mixed conducting mediator film (Ppy-HPA) is necessary to provide transfer of $\mathrm{H}^{+}$through the different interfaces and to study the proton transport in a PFSA ionomer which is only an ionic conductor. In an acidic solution, the reactions associated with the reduction of HPA trapped in Ppy matrix can be represented as:

$$
\begin{aligned}
& \mathrm{SiMo}^{\mathrm{VI}}{ }_{12} \mathrm{O}_{40}{ }^{4-}+2 \mathrm{H}^{+}+2 \mathrm{e}^{-} \leftrightarrows \mathrm{H}_{2} \mathrm{SiMo}^{\mathrm{VI}}{ }_{10} \mathrm{Mo}^{\mathrm{V}}{ }_{2} \mathrm{O}_{40}{ }^{4-} \\
& \mathrm{H}_{2} \mathrm{SiMo}^{\mathrm{VI}}{ }_{10} \mathrm{Mo}_{2}{ }_{2} \mathrm{O}_{40}{ }^{4-}+2 \mathrm{H}^{+}+2 \mathrm{e}^{-} \leftrightarrows \mathrm{H}_{4} \mathrm{SiMo}_{8} \mathrm{Mo}_{4} \mathrm{~V}_{4} \mathrm{O}_{40}{ }^{4-}
\end{aligned}
$$

Under a cathodic polarization, HPA is reduced and the required protons for charge compensation are transported through the Nafion or Nafion-CS-SO $3{ }_{3} \mathrm{H}$ layer in contact with the electrolyte and reach the Ppy-HPA/proton conducting film interface (Fig. 1a-d). Fig. 1a and 1b present the FEG-SEM images of the Ppy-HPA/Nafion and Ppy-HPA/Nafion-CS-SO $3{ }_{3} \mathrm{H}$ bilayers that are fairly homogeneous with an average thickness of one micrometer. The various interfaces considered in our study are schematized in Fig. 1c and 1d corresponding to the bilayer configurations studied. These schemes help us to construct the model (see theoretical part) explaining the EIS results and are presented below. EIS responses, for the bilayer configurations, present a classical shape as already shown in previous papers [8 a-d], and are presented in Fig. 1 e and f. High frequency values correspond to the electrolyte resistance, intermediate frequencies, showing a $45^{\circ}$ slope, to the proton transport in the proton conducting layer and the low frequency response to the proton transfer at the Ppy-HPA/proton conducting layer interface. To extract the diffusion coefficient, a model described in the theoretical section was used. A fitting procedure was employed to determine the various parameters and particularly the $D_{H}{ }^{+}$of each film studied. The most pertinent frequency range to calculate the transverse diffusion coefficient $\left(D_{H}{ }^{+}\right)$is located at the medium frequency range (between $1 \mathrm{kHz}-10 \mathrm{~Hz}$ ) where a fairly good fitting is obtained between the experimental 
and the theoretical curve (Fig. 1 e and f). Values are given in Table 1 for the Ppy-HPA/Nafion-CS-SO 3 and Ppy-HPA/Nafion bilayers. Then, the $\sigma_{H}{ }^{+}$of the proton conducting layers can be calculated using the Nernst-Einstein equation [10], as shown in the experimental part (Eq. 2). For these calculations, the $C_{H}{ }^{+}$ values which were determined by the ion-exchange-capacity (IEC) and sample dimensions were inserted in Eq. 2, assuming that the IEC values of the bulk membranes are the same as that of proton conducting films. The ${\sigma_{H}}^{+}$of the Nafion and Nafion-CS-SO 3 H composite layers was estimated as 15 and $59 \mathrm{mS} \mathrm{cm}^{-}$ ${ }^{1}$, respectively (Table I).

To evaluate the effect of the additives, the proton conductivity ratio, $\frac{{\sigma_{H}}^{+}(\mathrm{Nafion}+\mathrm{CS})}{{\sigma_{H}}^{+}(\mathrm{Nafion})}$, is calculated for pristine Nafion and Nafion-CS-SO 3 H composite films which is $\sim 3.9$. In this calculation, two experimental ratios were used: a diffusion coefficient ratio, $\frac{D_{H}{ }^{+}(\text {Nafion }+C S)}{\left.D_{H}{ }^{+} \text {(Nafion }\right)}$, of 3.0 and a proton concentration ratio, $\frac{C_{H}{ }^{+}(\text {Nafion }+C S)}{\left.C_{H}{ }^{+} \text {(Nafion }\right)}$, of 1.3. Thus, the proton conductivity of the composite films is increased not because of a significant increase in the concentration of the protons, but more likely due to an increase in the mobility of protons as a consequence of the better connectivity of the $-\mathrm{SO}_{3} \mathrm{H}$ groups in the presence of additives. Thus, more than 3 times enhanced $\sigma_{\mathrm{H}}{ }^{+}$is mainly correlated to the $\sim 3$ times higher proton diffusion coefficient in the presence of $\mathrm{CS}-\mathrm{SO}_{3} \mathrm{H}$.

As a comparison to the micrometric films, free-standing membranes were fabricated in the presence and absence of $5 \mathrm{wt} \% \mathrm{CS}-\mathrm{SO}_{3} \mathrm{H}$. The FEG-SEM image of the surface and the cross-section of the membranes (Fig. 2a, b) revealed that they are fairly homogeneous and dense throughout their thickness and the presence of $\mathrm{CS}-\mathrm{SO}_{3} \mathrm{H}$ does not lead to a too apparent macroscopic phase-separation. Their bulk conductivities were measured at $30{ }^{\circ} \mathrm{C}$ for various $\mathrm{RH}$ values using an Agilent impedance analyzer as described in the experimental section. The resistance values were determined from the electrical impedance diagrams in Nyquist representation at $30{ }^{\circ} \mathrm{C}$ and at various \% $\mathrm{RH}$ levels (30-90\% $\mathrm{RH}$ ) by extrapolating the resistance value regarding the low frequency limit of the first semi-circles (Fig. $2 \mathrm{c}$ and 
d). Then, the proton conductivity, ${\sigma_{\mathrm{H}}}^{+}$, is calculated using the relation given in the experimental part. The $\sigma_{\mathrm{H}}{ }^{+}$values are presented as a function of $\% \mathrm{RH}$ in Fig. 2e, which indicates that ${\sigma_{\mathrm{H}}}^{+}$of the composite Nafion/CS-SO 3 H membranes are almost 3 times higher than that of Nafion (measured with the same setup) at every \% RH level exposed.

Similar to the case of the composite films, characterized through the EIS technique, the proton conductivity ratio, $\frac{\sigma_{H}^{+}(\text {Nafion }+C S)}{\left.\sigma_{H}{ }^{+} \text {(Nafion }\right)}$, is also calculated taking the resistance values obtained at a $\mathrm{RH}$ of 90\% (Fig. 2 e). These conditions selected were as close as possible to that for full bath measurements used in the case of the bilayer composite films. A ratio of 3.2 is obtained which shows a fairly good agreement with the ratio estimated previously for the micrometric films (ratio of 3.9).

The advantage of the Nafion/CS-SO 3 H composite (both films and bulk membranes) is that without significantly increasing the IEC and thus, without excessive swelling $\left(0.9 \mathrm{mmol} \mathrm{g}^{-1}\right.$ and $1.2 \mathrm{mmol} \mathrm{g}^{-1}$, in the absence and presence of the additives, respectively (Table I)), the ${\sigma_{H}}^{+}$is increased almost 3 times. The present study based on the electrochemical impedance highlights that the proton conductivity enhancement with the $\mathrm{CS}-\mathrm{SO}_{3} \mathrm{H}$ is directly connected to the diffusion properties - an increase in the mobility of protons and the connectivity of the protonic pathways provided by the $\mathrm{CS}-\mathrm{SO}_{3} \mathrm{H}$ additive.

\section{Conclusions}

Under the experimental conditions of this study, the proton conductivity evolution in free standing membranes and micrometric films is in the same order of magnitude. The present study indicates the strength of the EIS methodology with a bilayer configuration to estimate the proton diffusion and conductivity in micrometric films. In a next step, it will be interesting to perform similar measurements for nanometric thin films in order to understand the particular behavior of nanometric films as indicated in previous works [12-15]. This configuration allows the characterization of nanometric thin films to be performed whereas conventional electrical impedance spectroscopy cannot be used due to very small 
resistance values or poor mechanical properties of evaluated nanometric films. Additionally, the present methodology sheds light on the contribution of the additives to proton conducting materials. The proton conductivity of the composites is improved compared to pristine Nafion and even for the low \% $\mathrm{RH}$ values at $30^{\circ} \mathrm{C}$. Such improvements are mostly challenging with other additives such as the case for Laponite/Nafion composites where the beneficial contribution to ${\sigma_{H}}^{+}$is lost beyond a further decrease in relative humidity (below to $70 \%$ ) [16]. Preliminary tests at $35 \% \mathrm{RH}$ and $80{ }^{\circ} \mathrm{C}$ in $\mathrm{PEMFC}$ configuration demonstrated a slight improvement in the $\mathrm{I}-\mathrm{V}$ curves when the $\mathrm{CS}-\mathrm{SO}_{3} \mathrm{H}$ is present in Nafion. In the case of sulfonic acid modified chitosan, the additive is less significant in terms of an increase in proton concentration. The proton conductivity enhancement is mainly correlated to the proton mobility.

\section{Acknowledgements}

I.R. acknowledges "The Emmag Programme" for the financial support of her Ph.D. thesis. The authors thank Ms. Françoise Pillier for the FEG-SEM measurements.

\section{References}

[1] a) Steele BCH, Heinzel A (2001) Materials for fuel-cell technologies. Nature 414: 345-352 b) Bruce PG, Scrosati B, Tarascon J-M (2008) Nanomaterials for rechargeable lithium batteries. Angew Chem Int Ed 47: 2930-2946 c) Manthiram A, Murugan AV, Sarkar A, Muraliganth T (2008) Nanostructured electrode materials for electrochemical energy storage and conversion. Energy Environ Sci 1: 621638

[2] a) Weber AZ, Mench MM, Meyers JP, Ross PN, Gostick JT, Liu QH (2011) Redox flow batteries: a review. J Appl Electrochem 41: 1137-1164 b) Inzelt G, Pineri M, Schultze JW, Vorotyntsev MA (2000) Electron and proton conducting polymers: Recent developments and prospects. Electrochim Acta 45:2403-2421 c) Kusoglu A, Kushner D, Paul DK, Karan K, Hickner MA, Weber AZ (2014) 
Impact of substrate and processing on confinement of Nafion thin films. Adv Func Mater 24: 47634774

[3] a) Mauritz KA and Moore RB (2004) State of understanding of Nafion. Chem Rev 104: 4535-4586 b) Hickner MA, Pivovar BS (2005) The chemical and structural nature of proton exchange membrane fuel cell properties. Fuel Cells 5: 213-229; c) Kraytsberg A, Ein-Eli Y (2014) Review of advanced materials for proton exchange membrane fuel cells. Energy Fuels 28: 7303-7330 d) Li X, Zhang H, Mai Z, Zhang H, Vankelecom I (2011) Ion exchange membranes for vanadium redox flow battery (VRB) applications. Energy Environ Sci 4: 1147-1160 e) Pintauro PN (2015) Perspectives on membranes and separators for electrochemical energy conversion and storage devices. Polymer Reviews 55: 201-207

[4] a) Ye G, Hayden CA, Goward GR (2007) Proton dynamics of Nafion and Nafion/ $\mathrm{SiO}_{2}$ composites by solid state NMR and pulse field gradient NMR. Macromolecules 40: 1529-1537 b) Zawodzinski TA, Neeman M, Sillerud LO, Gottesfeld S (1991) Determination of water diffusion coefficients in perfluorosulfonate ionomeric membranes. J Phys Chem 95: 6040-6044 c) Kidena K, Ohkubo T, Takimoto N, Ohira A (2010) PFG-NMR approach to determining the water transport mechanism in polymer electrolyte membranes conditioned at different temperatures. Eur Polymer J 46: 450-455

[5] a) Volino F, Pineri M, Dianoux AJ, De Geyer A (1982) Water mobility in a water-soaked nafion ${ }^{\circledR}$ membrane: A high-resolution neutron quasielastic study. J Polym Sci Polym Phys 20: 481-496 b) Pivovar AM, Pivovar BS (2005) Dynamic behavior of water within a polymer electrolyte fuel cell membrane at low hydration levels. J Phys Chem B 109: 785-793

[6] Devanathan R, Venkatnathan A, Dupuis MJ (2007) Atomistic simulation of nafion membrane: I. Effect of hydration on membrane nanostructure. J Phys Chem B 111: 8069-8079

[7] a) Ohkuba T, Kidena K, Takimoto N (2012) Molecular dynamics simulations of nafion and sulfonated poly ether sulfone membranes II. Dynamic properties of water and hydronium. J Mol Model 18: 533-540 b) Selvan ME, Keffer DJ, Cui S (2011) Reactive molecular dynamics study of 
proton transport in polymer electrolyte membranes. J Phys Chem C 115: 18835-18846 c) Devenathan R, Dupuis M (2012) Insight from molecular modelling: does the polymer side chain length matter for transport properties of perfluorosulfonic acid membranes? Phys Chem Chem Phys 14: 1128111295 d) Jorn R, Voth GA (2012) Mesoscale simulation of proton transport in proton exchange membranes. J Phys Chem C 116: 10476-10489

[8] a) Sel O, To Thi Kim L, Debiemme-Chouvy C, Gabrielli C, Laberty-Robert C, Perrot H, Sanchez C (2010) Proton insertion properties in a hybrid membrane/conducting polymer bilayer investigated by ac-electrogravimetry. J Electrochem Soc 157: F69-F76 b) To Thi Kim L, Sel O, Debiemme-Chouvy C, Gabrielli C, Laberty-Robert C, Perrot H, Sanchez C (2010) Proton transport properties in hybrid membranes investigated by ac-electrogravimetry. Electrochem Comm 12: 1136-1139 c) To Thi Kim L, Debiemme-Chouvy C, Gabrielli C, Perrot, H (2012) Redox switching of heteropolyanions entrapped in polypyrrole films investigated by ac electrogravimetry. Langmuir 38: 13746-13757 d) Dos Santos L, Laberty-Robert C, Marechal M, Perrot H, Sel O (2015) Proton diffusion coefficient in electrospun hybrid membranes by electrochemical impedance spectroscopy. Langmuir 36: 97379741

[9] a) Vaghari H, Jafarizadeh-Malmiri H, Berenjian A, Anarjan N (2013) Recent advances in application of chitosan in fuel cells. Sustain Chem Processes 1: 16-28 b) Varshney P, Gupta S (2011) Natural polymer-based electrolytes for electrochemical devices: a review. Ionics 17: 479483 c) Dash M, Chiellini F, Ottenbrite RM, Chiellini E (2011) Chitosan-a versatile semi-synthetic polymer in biomedical applications. Prog Polym Sci 36: 981-1014 d) Deng Y, Helms BA, Rolandi CM (2015) Synthesis of pyridine chitosan and its protonic conductivity. J Polym Sci Part A: Polym Chem 53: 211-214

[10] Bockris J, Reddy A (1970) Modern electrochemistry. Bockris J (ed) Vol. 1, Plenum Press, New York, pp 374-382 
[11] Debiemme-Chouvy C, Rubin A, Perrot H, Deslouis C, Cachet H (2008) ac-Electrogravimetry study of ionic and solvent motion in polypyrrole films doped with a heteropolyanion, $\mathrm{SiMo}_{12} \mathrm{O}_{44}{ }^{-}$. Electrochim Acta 53: 3836-3843

[12] Siroma Z, Ioroi T, Fujiwara N, Yasuda K (2002) Proton conductivity along interface in thin cast film of Nafion. Electrochem Comm 4: 143-145

[13] Paul DK, Fraser A, Karan K (2011) Towards the understanding of proton conduction mechanism in PEMFC catalyst layer: conductivity of adsorbed Nafion films. Electrochem Comm 13: 774-777

[14] Paul DK, Karan K, Docoslis A, Giorgi JB, Pearce J (2013) Characteristics of self-assembled ultrathin Nafion films. Macromolecules 46: 3461-3475

[15] Eastman SA, Sangcheol K, Page KA, Rowe BW, Kang S, DeCaluwe SC, Dura JA, Soles CL, Yager KG (2012) Effect of confinement on structure, water solubility, and water transport in nafion thin films. Macromolecules 45: 7920-7930

[16] Bebin P, Caravanier M, Galiano H (2006) Nafion ${ }^{\circledR} /$ clay- $\mathrm{SO}_{3} \mathrm{H}$ membrane for proton exchange membrane fuel cell application J. Membr. Sci. 278: 35-42

\section{Figure Captions}

Figure 1. FEG-SEM cross-section image of Ppy-HPA/Nafion (a) and Ppy-HPA/Nafion/CS-SO 3 H (b) films on gold electrodes and respective schematic representation of the working electrodes in contact with electrolyte (c and d). Electrochemical impedance spectroscopy results of Ppy-HPA/Nafion (e) and (f) Ppy-HPA/Nafion-CS-SO 3 H measured in $0.5 \mathrm{M} \mathrm{HClO}_{4}$ at $300 \mathrm{mV}$ vs SCE. The Eq. 1 was used to fit the experimental EIS data in panel e and $\mathrm{f}$.

Figure 2. FEG-SEM cross-section image of (a) Nafion and (b) Nafion/CS-SO $3 \mathrm{H}$ free standing membranes. Electrical impedance results at $90 \% \mathrm{RH}$ at $30^{\circ} \mathrm{C}\left(\mathrm{c}\right.$ and d) and the $\mathrm{H}^{+}$conductivity data at $30{ }^{\circ} \mathrm{C}$ as a function of relative humidity (\% RH) (e) of Nafion and Nafion/CS-SO $3 \mathrm{H}$ membranes. 


\section{Table Title}

Table 1. Characteristics of the membranes and bilayer structures with fitting parameters of the electrochemical impedance spectroscopy data in Fig. 1 e and f. 


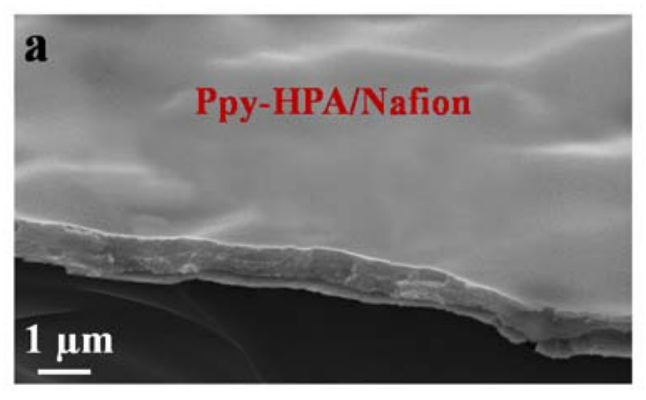

H+

c
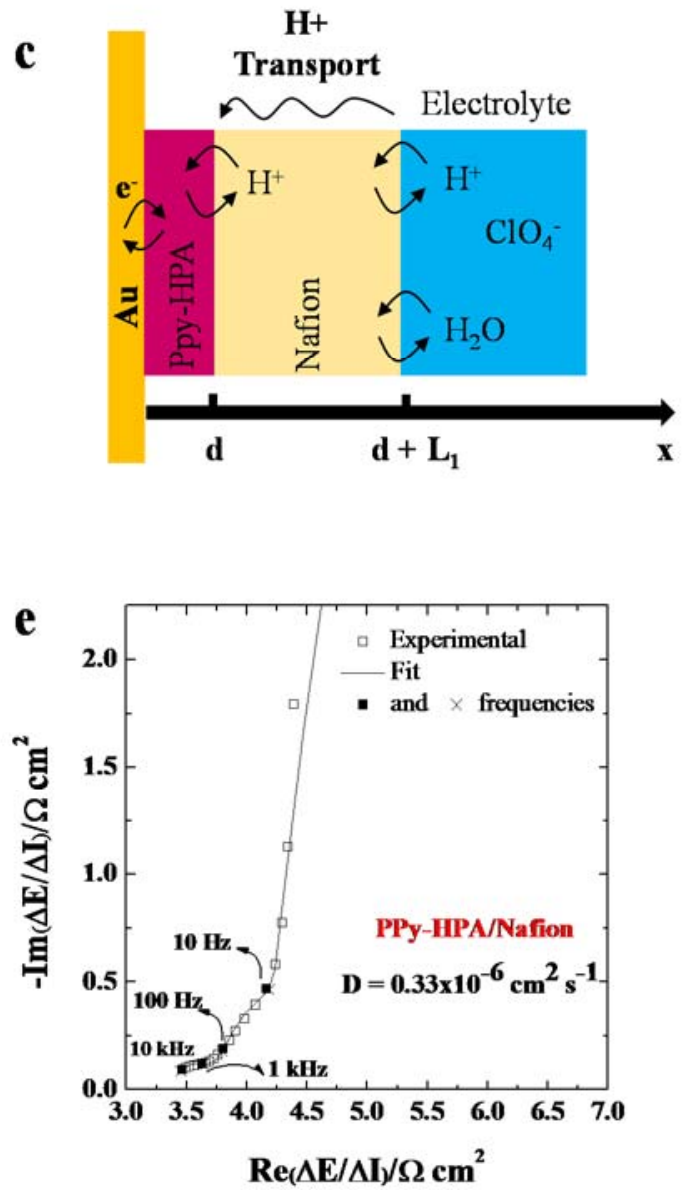
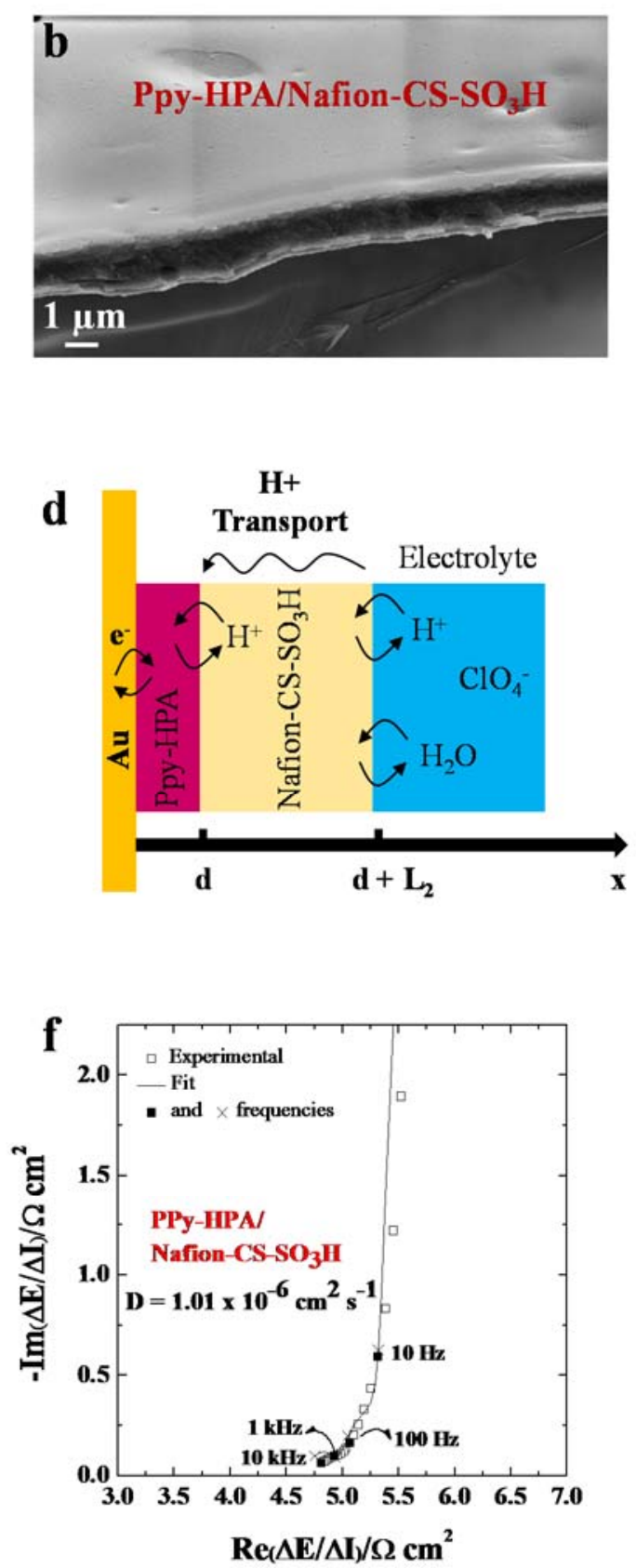

\section{Figure 1.}



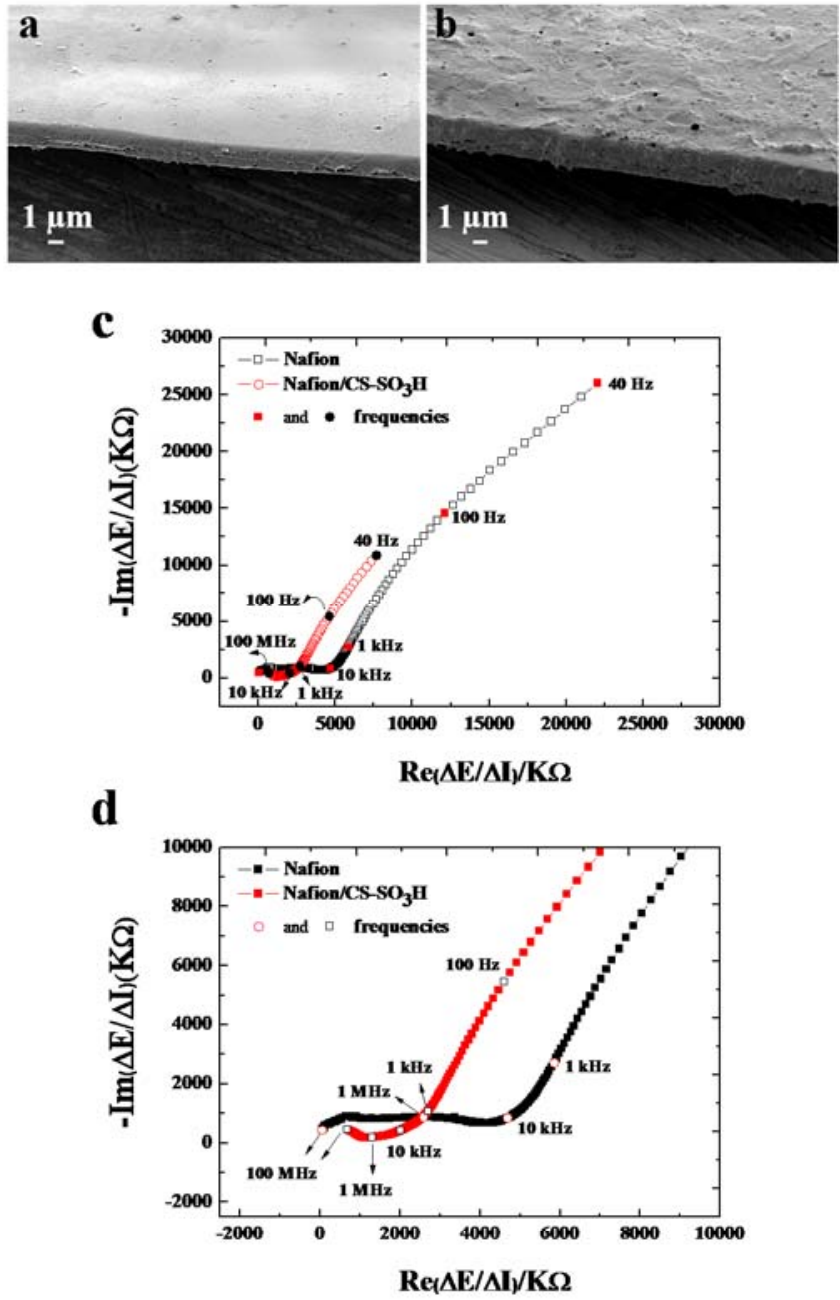

e

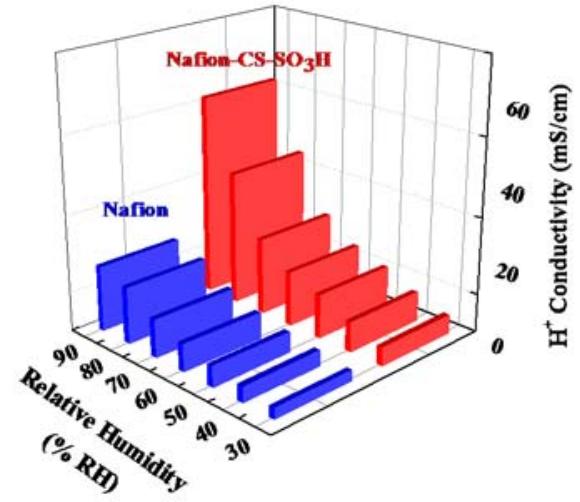

Figure 2. 
Table 1

\begin{tabular}{|c|c|c|c|c|}
\hline & Ppy-HPA/Nafion & $\begin{array}{c}\text { Ppy-HPA/Nafion-CS- } \\
\mathrm{SO}_{3} \mathrm{H}\end{array}$ & $\begin{array}{l}\text { Recast } \\
\text { Nafion }\end{array}$ & $\begin{array}{c}\text { Recast } \\
\text { Nafion-CS-SO }{ }_{3} \mathrm{H}\end{array}$ \\
\hline Thickness (L) ${ }^{[a]}$ & $0.75 \mu \mathrm{m}$ & $1.1 \mu \mathrm{m}$ & $30 \mu \mathrm{m}$ & $35 \mu \mathrm{m}$ \\
\hline$D_{H}^{+}\left(\mathrm{cm}^{2} \mathrm{~s}^{-1}\right)$ & $0.33 \times 10^{-6} \pm 0.03 \times 10^{-6}$ & $1.01 \times 10^{-6} \pm 0.10 \times 10^{-6}$ & - & - \\
\hline$I E C_{\exp }\left(\operatorname{meq~g}^{-1}\right)$ & - & - & 0.9 & 1.2 \\
\hline $\mathrm{Cb}_{[\mathrm{b}]}^{+}$(membrane) $\left(\mathrm{mmol} \mathrm{\textrm {cm } ^ { - 3 } )}\right.$ & 11.7 & 15.6 & 11.7 & 15.6 \\
\hline $\begin{array}{l}\sigma_{H^{+}}\left(\mathrm{mS} \mathrm{cm} \mathrm{cm}^{-1}\right) \\
\text { at } 30^{\circ} \mathrm{C}, 90 \% \mathrm{RH}\end{array}$ & $15^{[\mathrm{c}]}$ & $59^{[\mathrm{c}]}$ & $17^{[\mathrm{d}]}$ & $52^{[\mathrm{d}]}$ \\
\hline${ }_{\mathrm{K}^{+}}^{\text {PPyHPA/membrane }}$ & $1.42 \times 10^{-3} \mathrm{~cm} \mathrm{~s}^{-1}$ & $2.65 \times 10^{-3} \mathrm{~cm} \mathrm{~s}^{-1}$ & - & - \\
\hline${ }_{\mathrm{G}^{+}}^{\text {PPyHPA/membrane }}$ & $3.93 \times 10^{-5} \mathrm{~mol} \mathrm{~s}^{-1} \mathrm{~cm}^{-2} \mathrm{~V}^{-1}$ & $6.12 \times 10^{-5} \mathrm{~mol} \mathrm{~s}^{-1} \mathrm{~cm}^{-2} \mathrm{~V}^{-1}$ & - & - \\
\hline$M_{H^{+}}^{\text {PPyHPA/membrane }}$ & $1.13 \times 10^{-2} \mathrm{~cm} \mathrm{~s}^{-1}$ & $2.09 \times 10^{-2} \mathrm{~cm} \mathrm{~s}^{-1}$ & - & - \\
\hline
\end{tabular}

[a] Measurements are based on the FEG-SEM images (under the vacuum-dried conditions). [b] Calculated by using the ion-exchange-capacity (IEC) and sample dimensions. [c] Calculated from equation (4) using the $\mathrm{D}_{H}{ }^{+}$obtained from EIS measurements and proton concentrations in the Nafion and NafionCS- $\mathrm{SO}_{3} \mathrm{H}$ layers. [d] Measured with the electrical impedance spectroscopy at $30{ }^{\circ} \mathrm{C}$ and $90 \% \mathrm{RH}$. 